\title{
Neutron and X-ray Diffraction Residual Stress Measurements in Aluminium Alloys MIG Welded T-Joints after Friction Stir Processing
}

\author{
J.P. Nobre ${ }^{1,2, a^{*}}$, A.C. Batista ${ }^{1, b}$, J.R. Kornmeier ${ }^{3, c}$, J.D. Costa ${ }^{4, d}$, A. Loureiro ${ }^{4, e}$ \\ and J.S. Jesus ${ }^{4, f}$ \\ ${ }^{1}$ CEMDRX, Department of Physics, University of Coimbra, 3004-516 Coimbra, Portugal \\ ${ }^{2}$ School of Mechanical, Industrial and Aeronautical Engineering, University of the Witwatersrand, \\ WITS 2050, Johannesburg, South Africa \\ ${ }^{3}$ FRM-II, TU München, Lichtenbergstr. 1, 85747 Garching, Germany \\ ${ }^{4}$ CEMUC, Department of Mechanical Engineering, University of Coimbra, 3030-788 Coimbra, \\ Portugal \\ a joao.nobre@wits.ac.za, ${ }^{\text {b }}$ castanhola@fis.uc.pt, ${ }^{\mathrm{c}}$ Joana.Kornmeier@frm2.tum.de, \\ djose.domingos@dem.uc.pt, ${ }^{\mathrm{e}}$ altino.loureiro@dem.uc.pt, ${ }^{\mathrm{f}}$ joeldasilvadejesus@gmail.com \\ * Corresponding author
}

Keywords: Friction stir processing, MIG welding, residual stresses, neutron diffraction, X-ray diffraction.

\begin{abstract}
Friction Stir Processing (FSP) is a relatively new post-processing technique. Fatigue strength of MIG fillet welds of aluminium alloys can be substantially improved using FSP. Beyond other properties intrinsically tied to fatigue life, especially attention should be paid to the effect of the final residual stress state. In this study the residual stress distribution in T-joints of two aluminium alloys was determined by Neutron and X-ray diffraction. FSP effect on the residual stress state and fatigue life was analysed.
\end{abstract}

\section{Introduction}

Friction Stir Processing (FSP) is an emerging metalworking technique that can provide localized modification and control of microstructures in near-surface layers of processed metallic components. FSP was based on the principles of the Friction Stir Welding (FSW), a solid-state joining process, invented at the Welding Institute (TWI) (Cambridge, United Kingdom) in 1991 [1], for welding soft materials such as aluminium alloys. FSP was developed for microstructural modification based on the FSW principles [2]. FSP is a solid-state processing technique that with one step processing achieves microstructure refinement, densification and homogeneity. Besides, the microstructure and mechanical properties of the processed zone can be accurately controlled by optimizing the tool design, FSP parameters, and active cooling/heating [3].

In previous work [4], the fatigue resistance of AA6082 friction stir welds was analysed. Detailed examination revealed a hardness decrease in the thermo-mechanically affected zone and the nugget zone average hardness was found to be lower than the base alloy hardness. The comparison with data collected from the literature shows that FSW specimens present higher fatigue resistance than specimens welded by MIG (Metal Inert Gas) and TIG (Tungsten Inert Gas) processes, but have significantly lower lives than the base material [4]. Furthermore, the characteristic curve obtained for friction stir welds is higher than the International Institute of Welding (IIW) fatigue class for fusion welds with full-penetration both-sided butt joints. Another performed work [5] analysed the validity of Miners's and Manson-Halford's damage rules applied to FSW welded specimens under constant and variable amplitude loadings with stress ratios $\mathrm{R}$ of 0 and -1 . As expected, a significant mean stress influence was observed. The comparison of experimental fatigue lives with predictions calculated with both Miners's and Manson-Halford's Damage Rules, revealed a good agreement for $\mathrm{R}=0$. Under $\mathrm{R}=-1$ both damage predictions methods were in general non conservative. In addition, preliminary results obtained on the effect of FSP after MIG welding process in an aluminium 
alloy [6] have shown that FSP does not change significantly the hardness and mechanical strength of the weld, but slightly improves its ductility. However, an improvement of fatigue strength has been observed, probably due to microstructure's refinement and eventual residual stresses decrease. In fact, the study of FSP residual stresses and its evolution during cyclic loading was never accomplished in the past and was the aim of the present research. In this context, the use of the neutron diffraction technique, to determine, non-destructively, the in-depth residual stress distribution, will be essential. In some cases, the measurements were completed by the use of the $\mathrm{X}$-ray diffraction technique to access the residual stresses in the surface near layers. Therefore, a complete characterisation of the residual stress state, before and after FSP on MIG fillet welds of aluminium alloys, and how it evolves during cyclic loading was performed and will be presented in the following. Fatigue tests have been carried out under constant amplitude loading with different stress ratios $\mathrm{R}$.

\section{Materials and Experimental Procedures}

In the present research two aluminium alloys AA6082-T651 and AA5083-H111 will be considered. Table 1 shows the mechanical properties and chemical composition of both alloys. Fillet welds (T-joints) were performed on $6 \mathrm{~mm}$ thick plates $(160 \times 160 \times 6 \mathrm{~mm})$. For both alloys, some specimens were only MIG welded; other specimens were subjected to MIG welding followed by friction stir processing. Some of these specimens were also subjected to cyclic loading. $20 \mathrm{~mm}$ width specimens were taken for fatigue tests and residual stress measurements, as shown in Fig. 1.

Table 1. Mechanical properties and chemical composition of the aluminium alloys

\begin{tabular}{|c|c|c|c|c|c|c|c|c|c|c|c|c|}
\hline \multirow{2}{*}{ Material } & \multirow{2}{*}{$\begin{array}{c}\boldsymbol{\sigma}_{\mathrm{YS} 0.2} \\
{[\mathrm{MPa}]}\end{array}$} & \multirow{2}{*}{$\begin{array}{c}\boldsymbol{\sigma}_{\text {UTS }} \\
{[\mathrm{MPa}]}\end{array}$} & \multirow{2}{*}{$\begin{array}{c}\boldsymbol{\varepsilon}_{\mathbf{R}} \\
{[\%]}\end{array}$} & \multirow{2}{*}{$\mathbf{H V}_{0.2}$} & \multicolumn{8}{|c|}{ Chemical Composition [\% weight] } \\
\hline & & & & & $\mathrm{Si}$ & $\mathrm{Mg}$ & $\mathrm{Mn}$ & $\mathrm{Fe}$ & $\mathrm{Cr}$ & $\mathrm{Cu}$ & $\mathrm{Zn}$ & $\mathrm{Ti}$ \\
\hline $\begin{array}{c}\mathbf{A A 5 0 8 3} \\
\text { H111 }\end{array}$ & 158 & 320 & 23.7 & 80 & $<0.4$ & 4.5 & 1.0 & 0.4 & 0.05 & 0.1 & 0.25 & 0.15 \\
\hline $\begin{array}{c}\text { AA6082 } \\
\text { T651 }\end{array}$ & 307 & 330 & 10 & 115 & 1.05 & 0.8 & 0.68 & 0.26 & 0.01 & 0.04 & 0.02 & 0.01 \\
\hline
\end{tabular}
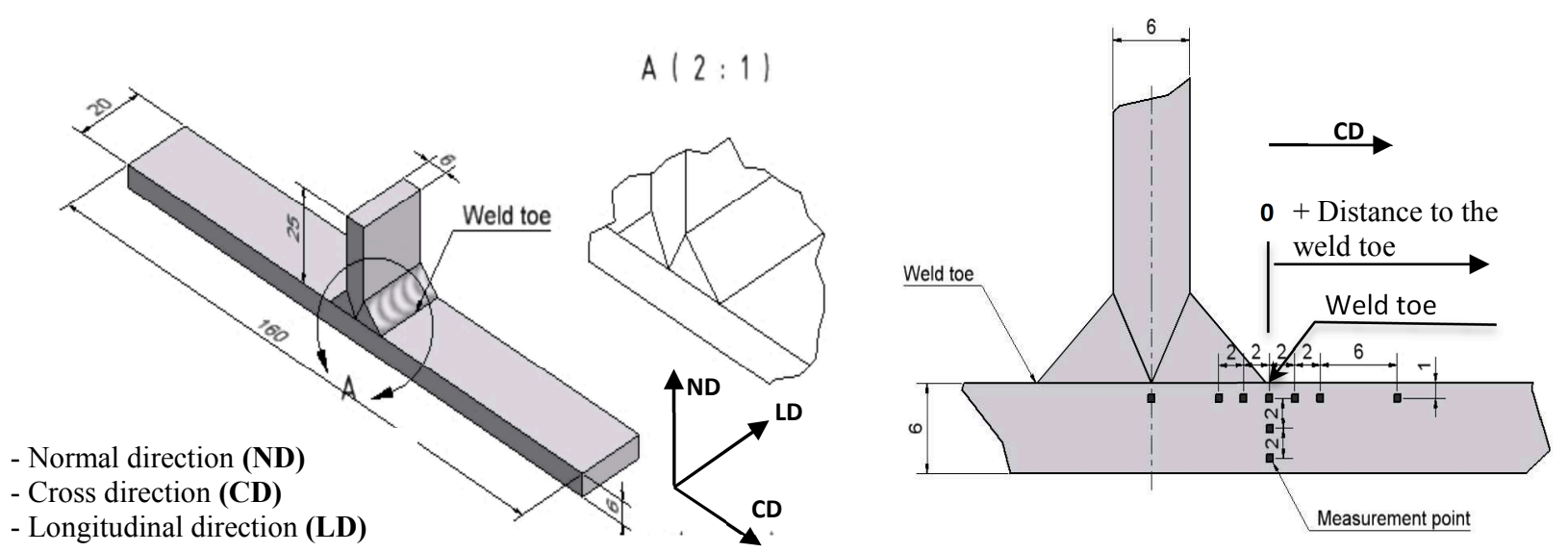

Fig. 1 Specimens' geometry (left) and relative position of measurement points for neutron diffraction analysis (right). The measurement referential is also shown.

Residual stresses in a maximum of six points close to the surface ( $\sim 1 \mathrm{~mm}$ depth) have been determined by neutron diffraction, in the centre of the specimens (at mid wide section), as shown in Fig. 1. In addition, at the weld toe, in-depth residual stresses were determined considering two additional points, as also shown in Fig. 1 (right). These measurements were performed before and after the friction stir post-processing treatment in each aluminium alloy. A total of four specimens were analysed before the fatigue tests. For studying the evolution of residual stress state during cyclic loading, two additional measurements were also performed; one after, approximately, 100 loading cycles and other after 10,000 loading cycles, for a previous selected loading amplitude. In these cases, only the residual stress evolution at weld toes was analysed. 
The residual stress determination by neutron diffraction was performed at the nuclear reactor FRM II, at the Technical University of Munich, Germany, using the instrument STRESS SPEC, specifically developed and designed for the study of textures and residual stresses [7]. A monochromatic neutron beam with a wavelength of $1.74 \AA$ was used. The analysis of residual stresses was performed using the diffraction peak corresponding to the crystallographic planes $\{311\}$ and a diffraction angle of $2 \theta \approx 90.5^{\circ}$. In each measurement, a $1 \times 1 \times 1 \mathrm{~mm}^{3}$ gauge volume of irradiated material was characterised for measurements in the longitudinal direction of the weld. The measurements in the normal and cross directions were performed with a $1 \times 1 \times 10 \mathrm{~mm}^{3}$ gauge volume of irradiated material, oriented in the longitudinal direction. The diffraction profiles were fitted by a Gaussian function to determine their peak positions, 2 $\theta$. They where then converted to lattice spacing $\mathrm{d}_{\mathrm{hkl}}$ using the Bragg's law:

$$
n \lambda=2 d_{h k l} \sin \theta
$$

where $\lambda$ is the wavelength of the neutron radiation and $n$ is the order of diffraction. The elastic strains were then calculated by:

$$
\varepsilon=\frac{d_{k k l}-d_{0}}{d_{0}} \cong-\Delta \theta \sqsubset \cot \theta_{0},
$$

where $d_{0}$ is the lattice spacing of the sample in the stress free state and $\theta_{0}$ is the corresponding diffraction angle. Strain measurements were made in the three principal directions for each point, in order to fully define the stress tensor given by the generalised Hooke's law [8]:

$$
\sigma_{i}=\frac{E_{h k l}\left(1-v_{h k l}\right)}{\left(1+v_{h k l}\right)\left(1-2 v_{h k l}\right)} \varepsilon_{i}+\frac{v_{h k l} E_{h k l}}{\left(1-2 v_{h k l}\right)\left(1+v_{h k l}\right)} \sum_{j} \varepsilon_{j} \quad, j=1,2,3 \quad \text { and } j \neq i \text {, }
$$

being $\sigma_{\mathrm{i}}$ and $\varepsilon_{\mathrm{i}}$ the stresses and strains in the principal directions. $\mathrm{E}_{\mathrm{hkl}}$ and $v_{\mathrm{hkl}}$ are the Young's modulus and Poisson's ratio, respectively, in the direction perpendicular to the crystallographic planes $\{\mathrm{hkl}\}$. The following elastic constants were used: $\mathrm{E}_{\{311\}}=69 \mathrm{GPa}$ and $\mathrm{v}_{311}=0.32$ [9]. For the determination of the parameter $\mathrm{d}_{0}$ of the samples, which characterises the material without stresses, small cubes of $1.75 \mathrm{~mm}$ edge, representative of the material at the different analysed depths, were cut from each sample by electric discharge machining (see Fig. 2).
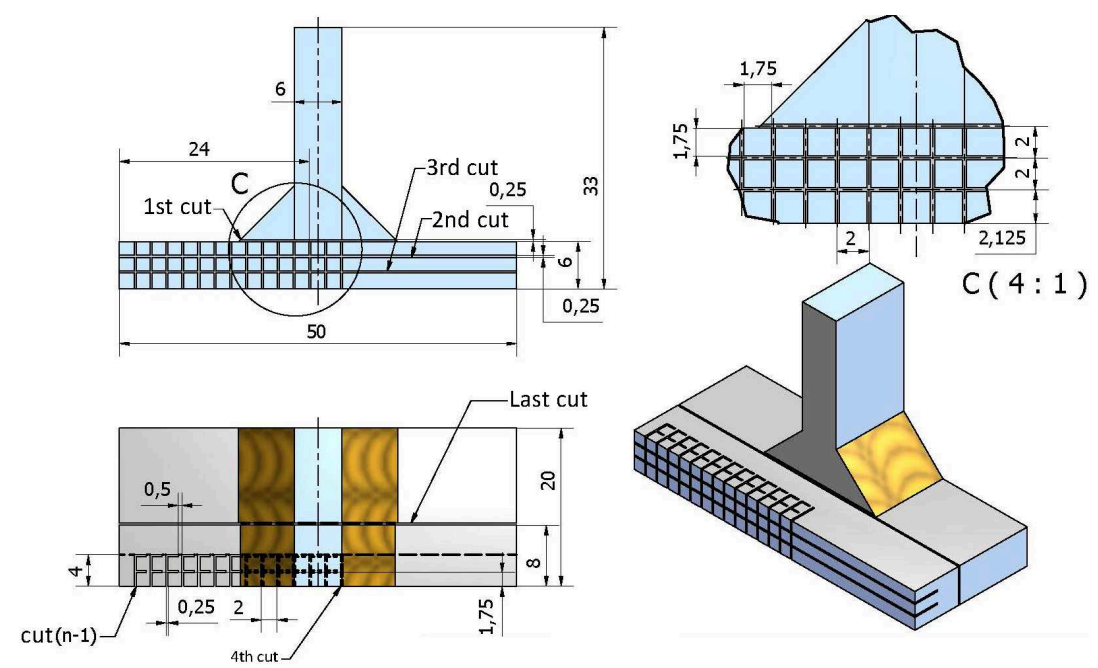

Fig. 2 Design for manufacturing the "comb" with small cubes necessary to determine the interplanar spacing of the stress free state, $\mathrm{d}_{0}$. 
With this procedure it is intended and it is assumed that the cubes are left without stresses, being considered for obtaining the reference value $\mathrm{d}_{0}$ for each measuring depth. For an accurate reference of the position of the measured point at a given depth, it was decided to maintain the cubes partially linked to each other, as shown in Fig. 2.

The residual stress analysis at the surface of the samples was performed by X-ray diffraction using a Proto iXRD equipment. Lattice deformations of the $\{222\}$ diffraction planes $\left(2 \theta \approx 157^{\circ}\right)$ were measured using $\mathrm{Cr}-\mathrm{K} \alpha \mathrm{X}$-ray radiation. The stress was evaluated with an elliptical regression of $d$ vs. $\sin ^{2} \psi$ data and the $(1 / 2) \cdot \mathrm{S}_{2} \mathrm{X}$-ray elastic constant value of $18.56 \times 10^{-6} \mathrm{MPa}^{-1}$.

\section{Experimental Results and Discussion}

In the results presented in the following, only the residual stresses in the cross direction to the welding beads will be considered. This is the direction of the applied cyclic loading and, therefore, the most important direction to analyse the fatigue strength of the welded T-joints considered.

Fig. 3 (left) shows the residual stress distribution around the weld toe, at $1 \mathrm{~mm}$ depth, for the case of Al5083 alloy, after the MIG welding procedure and after MIG welding followed by friction stir processing (FSP), respectively. In this case it is observed that FSP processing increases the residual stresses initially induced by the MIG welding process. In the weld toe the residual stress becomes more tensile, increasing from $10 \mathrm{MPa}$ till about $50 \mathrm{MPa}$. This behaviour is observed in all points analysed.
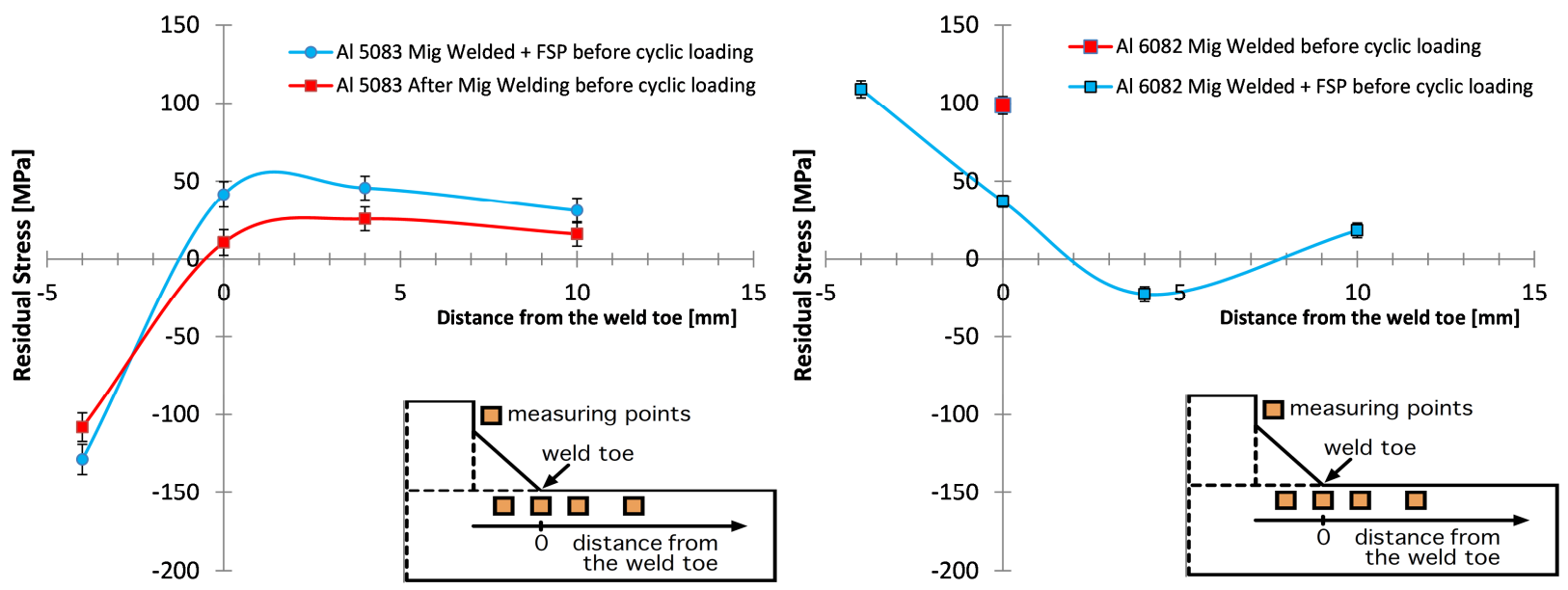

Fig. 3 Distribution of the residual stresses in the cross direction relatively to the welding beads, at $1 \mathrm{~mm}$ depth, for the case of A15083 alloy (left) and A16082 (right)

In the case of A16082 alloy a complete different behaviour is observed, as shown in Fig. 3 (right). First, below the weld bead the residual stress after MIG welding process is high tensile with values above $120 \mathrm{MPa}$, not seen in Fig 3 (right), while in the case of Al5083 the value is high compressive with a value around $-120 \mathrm{MPa}$. In addition, in this case, it is observed a clear residual stress relaxation in the weld toe, after the FSP treatment.

The behaviour described above can also be confirmed by the values of the in-depth residual stress distribution in the zone of the weld toe. Fig 4 shows the results of the in-depth residual stress distribution after the MIG welding process and after MIG welding process followed by FSP. Fig. 4 (left) shows the residual stress distribution for the case of A15083 alloy. The points at surface were determined by X-ray diffraction. In this material, it is clear that the FSP treatment induces an increase of the residual stresses. At weld toe, the initial low tensile residual stress of around +10 $\mathrm{MPa}$ becomes more tensile with a value around $+50 \mathrm{MPa}$ (values determined by neutron diffraction at $1 \mathrm{~mm}$ depth). On the contrary, for the case of Al6082 alloy, a clear residual stress relaxation is observed due to the FSP treatment. At the weld toe the residual stress decreases from around +100 
$\mathrm{MPa}$ to approximately $+30 \mathrm{MPa}$ (values determined by neutron diffraction at $1 \mathrm{~mm}$ depth). At surface residual stress changes from compressive to slightly tensile.
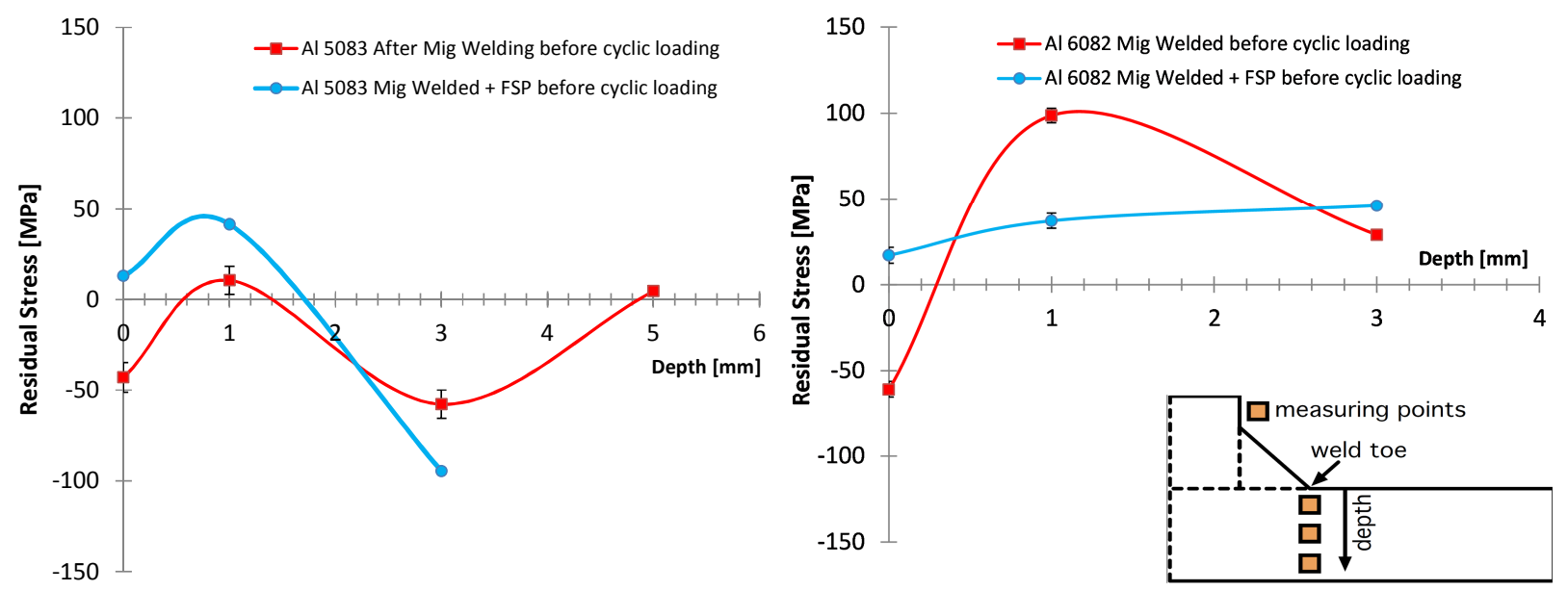

Fig. 4 In-depth distribution of the residual stresses in the cross direction of the welding beads, at the weld toe zone, for the case of A15083 alloy (left) and Al6082 (right)

The effect of the cyclic loading on the final residual stress state (stabilized stresses) can be observed in Fig. 5. Only the residual stress results in the zone of the weld toe are shown, since a similar behaviour for the residual stress results at different distances from the weld toe was found. For the A15083 alloy, no substantial evolution on the final residual stresses values in the direction of the applied cyclic loading (cross direction to the weld bead), and after 10,000 loading cycles, has been observed. However, in the case of A16082 alloy, a clear residual stress relaxation can be observed. After 10,000 cycles, and for the case of MIG welding followed by FSP, the residual stress values are very low, which means that they only have a minor effect on the final mean stress.
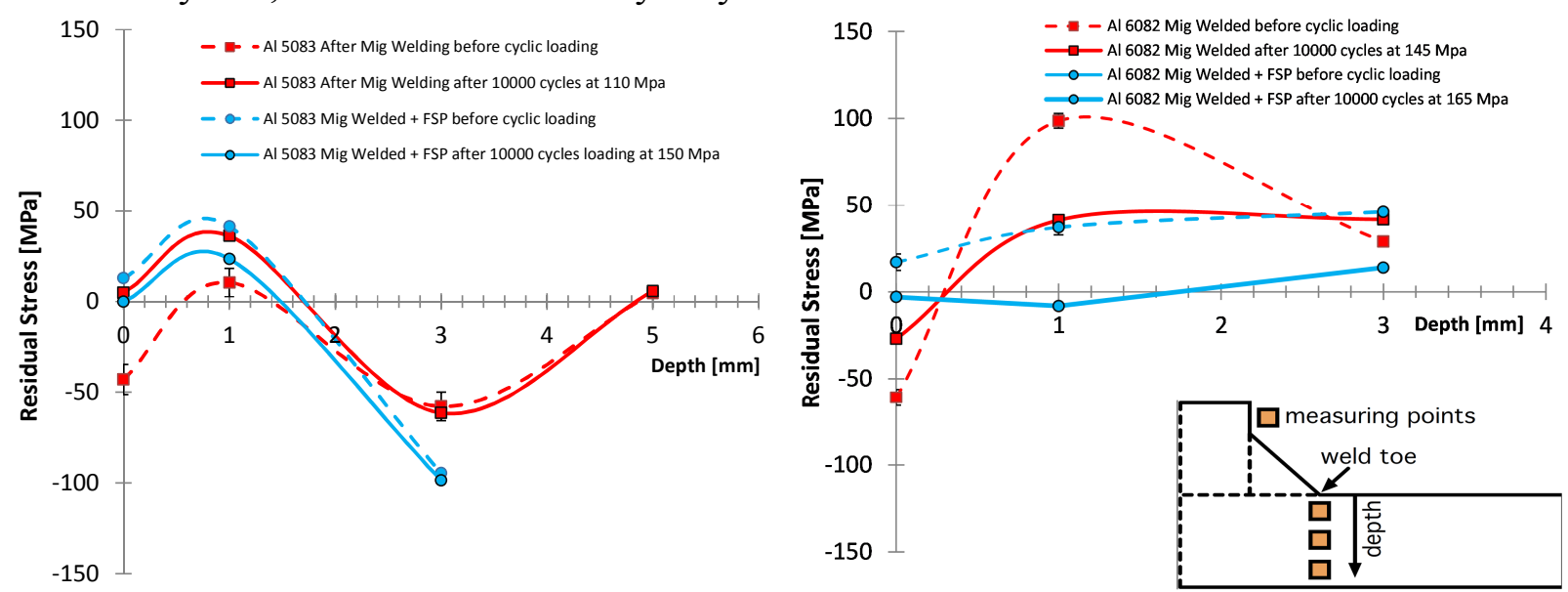

Fig. 5 In-depth residual stresses, in the cross direction of the welding beads, at the weld toe zone, for the case of Al5083 alloy (left) and Al6082 (right). Cyclic loading effect.

Fatigue tests have shown that the friction stir processing of the MIG welds promotes an important fatigue strength increase, for the stress ratios used, in comparison with unprocessed MIG cases, especially for higher fatigue lives. A significant influence of the mean stress was also observed, i.e., for the same stress range, specimens tested at stress ratios of $\mathrm{R}=-1$ present higher fatigue lives than specimens tested at $\mathrm{R}=0$ for both unprocessed and post-processed MIG welded specimens. A metallographic analysis made on the welding beads, for the case of A15083 alloy, is shown in Fig.6. It is possible to observe a clear grain refinement of the material's microstructure (Fig. 6a and 6c) in the region near the weld toe, as well as a welding defects removal and a decrease of curvature radius at weld toe, implying a decrease of the stress concentration effect at the weld root (Fig. $6 b$ and $6 d$ ). 

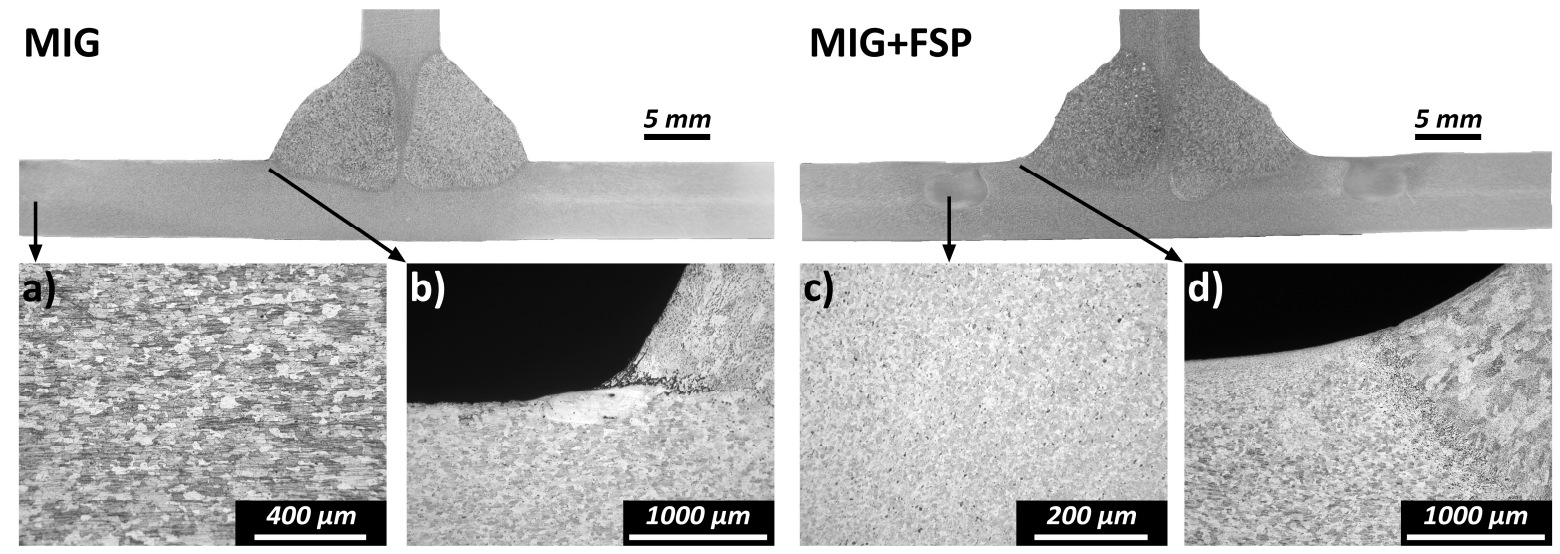

Fig. 6 Metallographic analysis of MIG welding beads (left) and MIG welding beads followed by friction stir processing (right) for the case of Al5083 alloy.

\section{Conclusions}

In the case of MIG welded T-Joints of Al5083 alloys, the increase of fatigue strength promoted by friction stir processing (FSP) cannot be explained by the beneficial effect of induced residual stresses. Other effects, such as, the microstructure grain refinement, reduction of stress concentration, the removal of previous welding defects and the slightly increases of hardness and mechanical strength should be the main causes for the fatigue strength improvement verified in this alloy. In the case of MIG welded T-Joints of A16082 alloys, it was observed a clear residual stress relaxation due to FSP treatment, beyond the above mentioned effects, thus contributing for the observed improvement of fatigue strength. In addition, it was observed that the cyclic loading also implies additional residual stress relaxation. The residual stresses stabilize during the first cycles applied, almost maintaining their values during the subsequent loading cycles.

\section{Acknowledgments}

The authors gratefully acknowledge the support of 7th Framework Programme of the European Community under the scope EC Research Infrastructures Action, EC Grant Agreement NMI3 and the support of the Heinz Maier-Leibnitz research neutron source (FRM II) facilities, Technique University of Munich, to the project 7184/2012. The authors also acknowledge the financial support of the Portuguese Government through "FCT Fundação para a Ciência e a Tecnologia" and the "ERDF European Regional Development Fund" through "Programa COMPETE/QREN", under the projects PTDC/EME-PME/114605/2009, Pest-C/FIS/UI0036/2011 and CENTRO-07-0224FEDER-002001 (MT4MOBI).

\section{References}

[1] W.M. Thomas, E.D. Nicholas et al. G.B. Patent Application No.9125978.8, Dec. 1991.

[2] R.S. Mishra and Z.Y. Ma: Mater. Sci. Eng., R, 50 (2005) 1-78.

[3] Z.Y. Ma, Metallurgical and Materials Transactions, A, 39A (2008) 642-658.

[4] J.D. Costa et al., International Journal of Structural Integrity, 2(2) (2011) 122-134.

[5] J.D. Costa et al., International Journal of Fatigue, 37 (2012) 8-16.

[6] J.D. Costa et al., Fatigue strength improvement of AA6082-T651 MIG butt welds subjected to friction stir processing. Communication presented at PCF2012, Coimbra, February 2-3, 2012.

[7] M. Hofmann et al., The New Materials Science Diffractometer STRESS-SPEC at FRM II, Mater. Sci. Forum, 524-525 (2006) 211-216.

[8] Viktor, H., Structural and Residual Stress Analysis by Nondestructive Methods: Evaluation, Application, Assessment, Elsevier Science B. V., Amsterdam, 1997.

[9] B. Eigenmann and E. Macherauch, Mat.-wiss. u. Werkstofftech., 27 (1996) 426-434. 